\title{
POTENTIAL OF RESAMPLED MULTISPECTRAL DATA FOR DETECTING DESMODIUM-BRACHIARIA INTERCROPPED WITH MAIZE IN A 'PUSH-PULL' SYSTEM
}

\author{
B.T. Mudereri ${ }^{1,2,3^{*}}$, E.M. Abdel-Rahman ${ }^{1,4}$, T. Dube ${ }^{2}$, T. Landmann ${ }^{1,5}$, S. Niassy ${ }^{1}$, H.E.Z. Tonnang ${ }^{1}$, Z.R. Khan ${ }^{1}$ \\ ${ }^{1}$ International Centre of Insect Physiology and Ecology (icipe), P.O. Box 30772, 00100 Nairobi, Kenya; *bmudereri@icipe.org; \\ eabdel-Rahman@icipe.org; sniassy@icipe.org; htonnang@icipe.org; zkhan@icipe.org \\ ${ }^{2}$ Department of Earth Sciences, University of Western Cape, Private Bag X17 Bellville 7535 South Africa; tidube@uwc.ac.za \\ ${ }^{3}$ Department of Animal and Wildlife Science, Midlands State University, P. Bag 9055, Gweru, Zimbabwe \\ ${ }^{4}$ Department of Agronomy, Faculty of Agriculture, University of Khartoum, Khartoum North 13314, Sudan \\ ${ }^{5}$ RSS-Remote Sensing Solutions Gmbh, Dingolfinger Str. 9, 81673 Munich, Germany; landmann@ rssgmbh.de
}

KEY WORDS: Cropping system; Field spectroscopy; Spectral resampling; Multispectral remote sensing

\begin{abstract}
:
Poor crop yields remain one of the main causes of chronic food insecurity in Africa. This is largely caused by insect pests, weeds, unfavourable climatic conditions and degraded soils. Weed and pest control, based on the climate-adapted 'push-pull' system, has become an important target for sustainable intensification of food production adopted by many small-holder farmers. However, essential baseline information using remotely sensed data is missing, specifically for the 'push-pull' companion crops. In this study, we investigated the spectral uniqueness of two of the most commonly used 'companion' crops (i.e. greenleaf Desmodium (Desmodium intortum) and Brachiaria (Brachiaria cv Mulato) with co-occurring soil, green maize, and maize stover. We used FieldSpec ${ }^{\circledR}$ Handheld $2^{\mathrm{TM}}$ analytical spectral device to collect in situ hyperspectral data in the visible and near-infrared region of the electromagnetic spectrum. Random forest was then used to discriminate among the different companion crops, green maize, maize stover and the background soil. Experimental 'push-pull' plots at the International Centre of Insect Physiology and Ecology (icipe) in Kenya were used as test sites. The in-situ hyperspectral reflectance data were resampled to the spectral waveband configurations of four multispectral sensors (i.e. Landsat-8, Quickbird, Sentinel-2, and WorldView-2) using spectral response functions. The performance of the four sensors to detect the 'push-pull' companion crops, maize and soil was compared. We were able to positively discriminate the two companion crops from the three potential background endmembers i.e. soil, green maize, and maize stover. Sentinel-2 and WorldView-2 outperformed (> 98\% overall accuracy) Landsat- 8 and Quickbird (96\% overall accuracy), because of their added advantage of the strategically located red-edge bands. Our results demonstrated the unique potential of the relatively new multispectral sensors' and machine learning algorithms as a tool to accurately discern companion crops from co-occurring maize in 'push-pull' plots.
\end{abstract}

\section{INTRODUCTION}

\subsection{Background}

Food security remains a challenge to millions of households in Africa and this is likely to worsen due to climate change and population growth (FAO, IFAD, UNICEF, WFP, 2019). One of the main sources of the chronic food insecurity observed in Africa is poor crop yields, largely caused by insect pests, weeds, unfavourable climatic conditions, and degraded soils (Khan et al., 2016). Weed and pest control, based on the 'push-pull' system, has become an important target for sustainable intensification of food production and adopted by many smallholder farmers (Khan et al., 2008). In the 'push-pull' strategy, specifically chosen companion plants are grown in between and around the main crop (Pickett et al., 2014), in our case it is maize. These companion plants release semiochemicals that (i) repel insect pests from the main crop using an intercrop which is the 'push' component; and (ii) attract insect pests away from the main crop using a trap crop which is the 'pull' component (Khan et al., 2016).

Although many small-scale farmers in Africa have welcomed and adopted the 'push-pull' system (Midega et al., 2015), identifying and evaluating the adoption rate and the improvement in yields has been conducted using rigorous and expensive field surveys, which have proven inconsistent, timeous and inaccurate (Khan et al., 2008; Midega et al., 2018).
Therefore, there is a need to develop spatially explicit, repeatable, and accurate methods that provide synoptic and near-real-time identification and quantification of the "pushpull' plots and their acreage. This structured information is important as it facilitates for the forecasting of the crop yield, growth, health, rotation, stress, and potential damage by insect pests or weather. Therefore, understanding the potential to map the various 'push-pull' components is a critical step towards achieving better detection and mapping accuracies that ensure strategic land use planning and wide-area mapping of the 'pushpull' approach.

Remote sensing provides an opportunity to accurately evaluate the intra-field variability within croplands, thus providing the needed capability to identify where the 'push-pull' system has been adopted and estimate their performance at large scales, with minimum cost (Mudereri et al., 2020a). Specifically, hyperspectral remote sensing provides several narrow and quasi contiguous bands that enhance the discrimination among different plant genera and species. This allows the possibilities to track the intra-field variabilities within croplands and thus improving detectability and separability of these variabilities (Adam et al., 2017; Mudereri et al., 2020b). However, essential baseline information using remotely sensed data of the most common climate-adapted companion crops i.e. the 'push' component; greenleaf Desmodium (Desmodium intortum) and Brachiaria (Brachiaria $c v$ Mulato) and their spectral pattern at canopy level is still rudimentary. 
On the other hand, the relatively new generation of multispectral space-borne sensors use relatively narrower wavebands (e.g. $\sim 15 \mathrm{~nm}$ spectral width), including those in the red-edge region of the electromagnetic spectrum (EMS) centred at 705,740 and $783 \mathrm{~nm}$ for Sentinel-2 and $724 \mathrm{~nm}$ for WorldView-2 that were not present in the previous broadband sensors like Landsat 7 and 8 (Chemura et al., 2017). Therefore, there has been a growing interest to test datasets from these sensors, regarding their potential to advance precision agriculture and other operational uses, particularly in lowincome regions (Dhau et al., 2018; Mudereri et al., 2019; Shoko and Mutanga, 2017).

\subsection{Companion crops in the 'push-pull' system}

In 'push-pull', maize is intercropped with the leguminous plant Desmodium which suppresses Striga through the roots and repels the stemborer moths "push". Brachiaria or Napier both popular fodder grasses is planted as a border around the field to attract female moth "pull". Desmodium produces volatile chemicals that attract predators of maize pests. A typical intercrop (push) and a companion (pull) crops in a 'push-pull' system are shown in Figure 1.
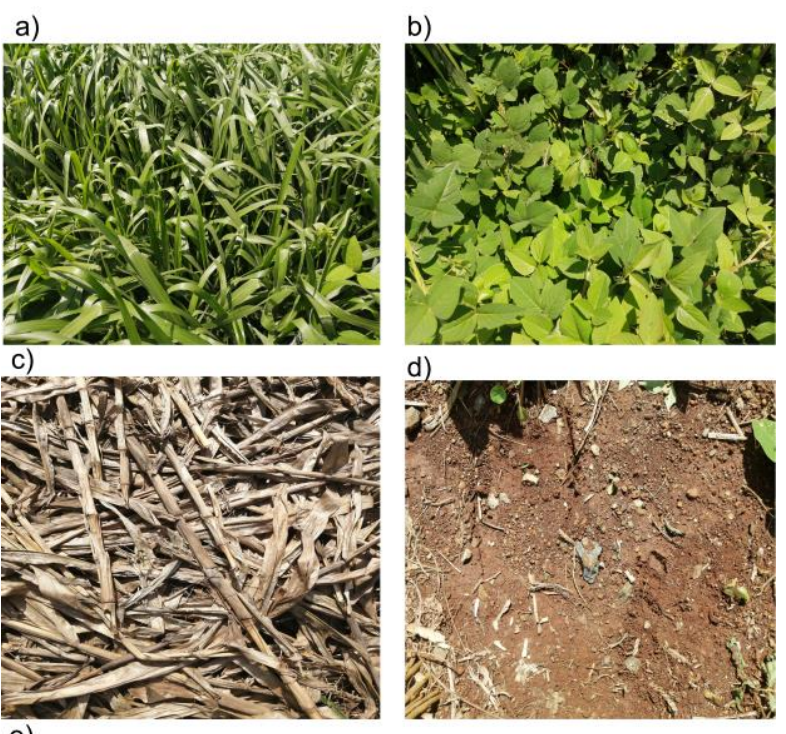

e)

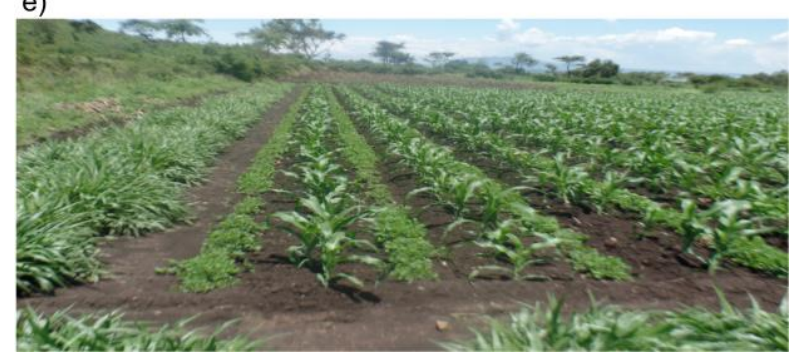

Figure 1. 'Push-pull' components and cropping system (a) Brachiaria (pull crop), (b) greenleaf Desmodium (push crop), (c) maize stover and (d) bare soil and (e) 'push-pull' cropping system.

There are a few variants of the 'push-pull' system using different companion crops such as silverleaf Desmodium $(D$. uncinatum) and Napier grass (Pennisetum purpureum). Although these companion crops were tested and found to be functional under different climatic conditions, they could not survive extended periods of drought (> 2 months) and higher temperatures $\left(>30^{\circ} \mathrm{C}\right)$, which are prevalent in most arid regions in Africa (Midega et al., 2015). However, studies have shown that Brachiaria species tolerate longer periods of droughts and temperatures more than $30^{\circ} \mathrm{C}$ (Pickett et al., 2014). Similarly, greenleaf Desmodium was found to tolerate higher temperatures with the ability to survive under drier conditions (Midega et al., 2015). Therefore, these two most commonly planted companion crops were incorporated into the climate-adapted 'push-pull' technology.

In this study, we investigated the spectral uniqueness of two most prominent companion plants (greenleaf Desmodium and Brachiaria) used in the climate-adapted 'push-pull' system with the co-occurring green maize crop (i.e. photosyntheticallyactive) and maize stover; and examined the potential of using the relatively new multispectral sensors to detect their spectral characteristics.

\section{METHODS}

\subsection{Study area}

Data were collected from on-station field experimental plots at the International Centre of Insect Physiology and Ecology (icipe) Duduville campus, in Nairobi Kenya. The experimental station is located at $1^{\circ} 13^{\prime} 26.39^{\prime \prime} \mathrm{S}$ and $36^{\circ} 53^{\prime} 47.21^{\prime \prime} \mathrm{E}$ at an altitude of $1600 \mathrm{~m}$. The climate of the study area is mainly subtropical, characterized by a yearly bimodal rainfall model with an average annual rainfall of $930 \mathrm{~mm}$. Rainfall occurs between March and June i.e. during 'long rains' season and a 'short rains' season spanning November to January. The annual average temperature is $18^{\circ} \mathrm{C}$ and the relative humidity ranges between $50 \%$ and $70 \%$.

\subsection{Spectral data collection}

The in-situ FieldSpec ${ }^{\circledR}$ Handheld $2^{\text {TM }}$ analytical spectral device (ASD), hyperspectral data in the visible and near-infrared (VNIR) region of the EMS was used to collect a single snapshot of the canopy-level field spectral data of the companion plants in the wavelength range between 325-1075 nm (750 narrow wavebands) following the detailed procedure outlined in the study of Mudereri et al., (2020b). In each of the two sampled maize fields $(10 \mathrm{~m} \times 10 \mathrm{~m})$, we laid out five quadrats measuring $1 \mathrm{~m} \times 1 \mathrm{~m}$ each along two crossing diagonal transects. Specifically, two quadrats were laid out across each of the two diagonal transects and $1 \mathrm{~m}$ away from the plot edges, while one quadrat was laid in the centre of the sample plot (Mudereri et al., 2020b). Using the 10 quadrats, we collected 200 spectra for each companion crop, soil, green maize ( $6^{\text {th }}$ leaf collar), and maize stover (dry) resulting in a total of 1000 spectra.

The spectral measurements acquired using the ASD were filtered using the 'noiseFiltering' function and smoothened using the 'Savitzky-Golay' filter in the 'hsdar' package (Lukas et al., 2018) in R software (R Core Team, 2020). These filtered spectra were resampled to the spectral configuration of relatively new four multispectral sensors; namely, WorldView2, Quick bird, Landsat-8, and Sentinel-2 using the spectral response function, i.e. 'SpectralResampling' present in the 'hsdar' package. Table 1 shows the band characteristics of the four multispectral sensors used and the specific bands that coincided with the limited data collected by the ASD instrument used (between $325 \mathrm{~nm}-1075 \mathrm{~nm}$ ). 


\begin{tabular}{|c|c|c|}
\hline Sensor & $\begin{array}{l}\text { No of } \\
\text { bands }\end{array}$ & Band centres (nm) \\
\hline Landsat-8 & 8 & $\begin{array}{l}\mathbf{4 4 4 . 5} ; \mathbf{4 8 2 . 5} ; \mathbf{5 5 7} ; \mathbf{6 5 5} \\
\mathbf{8 6 3 . 5} ; \quad 1372.5 ; \quad 1606 ; \\
2194.5\end{array}$ \\
\hline Quickbird & 4 & $485 ; 560 ; 660 ; 830$ \\
\hline Sentinel-2 & 13 & $\begin{array}{l}443 ; \mathbf{4 9 0} ; \mathbf{5 6 0} ; \mathbf{6 6 5} ; \mathbf{7 0 5} ; \\
\mathbf{7 4 0} ; \mathbf{7 8 3} ; \mathbf{8 4 2} ; \mathbf{8 6 5} ; \mathbf{9 4 5} \\
1375 ; 1610 ; 2190\end{array}$ \\
\hline WorldvView-2 & 8 & $\begin{array}{l}427 ; 478 ; 546 ; 608 ; 659 ; \\
724 ; 831 ; 908\end{array}$ \\
\hline
\end{tabular}

Table1. Band characteristics of the four multispectral sensors used in the analysis. The bold shows the bands used in this analysis

\subsection{Random forest discriminant algorithm}

The wavebands from these four multispectral sensors were tested as predictor variables in a random forest (RF) model to discriminate between the five 'push-pull' components from the Desmodium-Brachiaria-maize combination. RF algorithm has been widely used in classifying vegetation-related classes with reasonably high classification accuracies particularly when hyperspectral datasets were utilized (Abdel-Rahman et al., 2014). Further, RF algorithms do not require traditional regression assumptions, which makes it useful in many applications. The "Caret" package (Kuhn et al., 2018) in the R programming environment was used to execute and validate the model across the four data configurations of the multispectral sensors.

\subsection{Model evaluation}

The models' performance was evaluated using the inherent data partition function in the 'caret' package. This was done using a 10-fold cross-validation technique across all the data configurations of the four multispectral sensors. Model performance was presented, using boxplots of overall accuracy and Kappa across the four multispectral sensors.

\section{RESULTS}

\subsection{Spectral behaviour of five 'push-pull' system components}

Figure 2 demonstrates the variation in the spectral responses of the different 'push-pull' components at different hyperspectral wavelengths. In general, the five components tested showed many potential waveband regions, which are useful in their discrimination among the studied 'push-pull' components e.g. within the green, red-edge, and NIR (750-1075 nm) regions. The NIR revealed multiple and wide scattering within the leaf structure of the four vegetation components i.e. Brachiaria, Desmodium, green maize and maize stover. Nonetheless, the NIR displayed significant differences in magnitude with Desmodium producing the highest plateau of reflectance when compared to all other components. Compared to the maize stover and soil, the patterns of all the green vegetation (green maize and the companion crops) were similar in the whole spectrum but differed in the magnitude $(>2 \%$ difference between high and low).

Green maize dominated the visible range i.e. green and red waveband regions but exhibited a lower reflectance response than both Brachiaria and Desmodium in the NIR region (Figure 2). Although the Desmodium had the lowest reflectance in the red region of the spectrum, it had the steepest gradient in the red edge region compared to the Brachiaria and the green maize. On the other hand, the maize stover was conspicuously different as it showed higher reflectance across the visible bands but low in the NIR region (> 5\% difference between highest and lowest reflectance values). Although the pattern of the maize stover was like that of the soil, the maize stover spectra showed higher reflectance values compared to the soil across the entire tested spectrum (325-1075 nm)

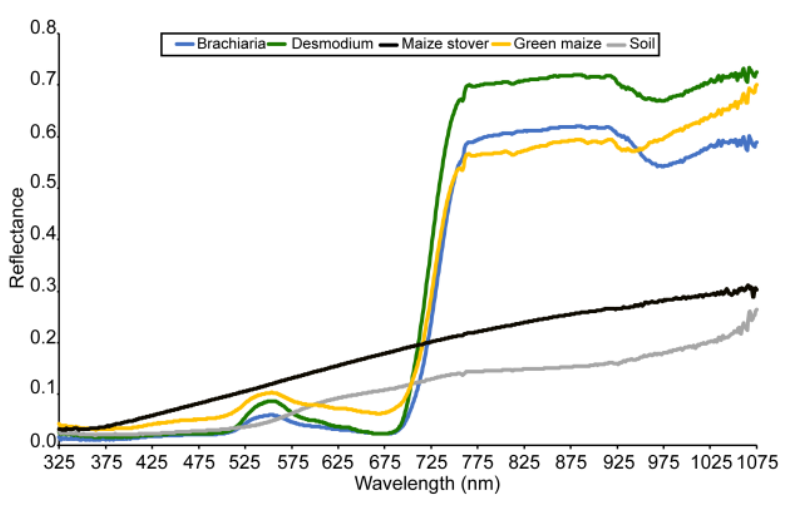

Figure 2. Mean canopy spectra of the 'push-pull' system components within the $325 \mathrm{~nm}-1075 \mathrm{~nm}$ wavelength spectrum

\section{2 'Push-pull' system components spectral behaviour using the band configurations of the four multispectral sensors}

The spectral trend of the behaviour of the tested 'push-pull' components while using the hyperspectral data was similar to the trend observed when the analysis was conducted across the four multispectral sensors. However, there are limitations of the number of bands within Landsat-8 $(\mathrm{n}=5)$ and Quickbird band $(n=4)$ configurations which reduced the data that could be extracted from them. Nonetheless, Figure 3 shows that there are various bands across the four multispectral sensors that have the potential for use in separating the spectra of the different 'pushpull' components. In particular, the strategically positioned rededge bands and the NIR of Sentinel-2 and WorldView-2 show the variation in the gradient of the spectral curves for the different components.
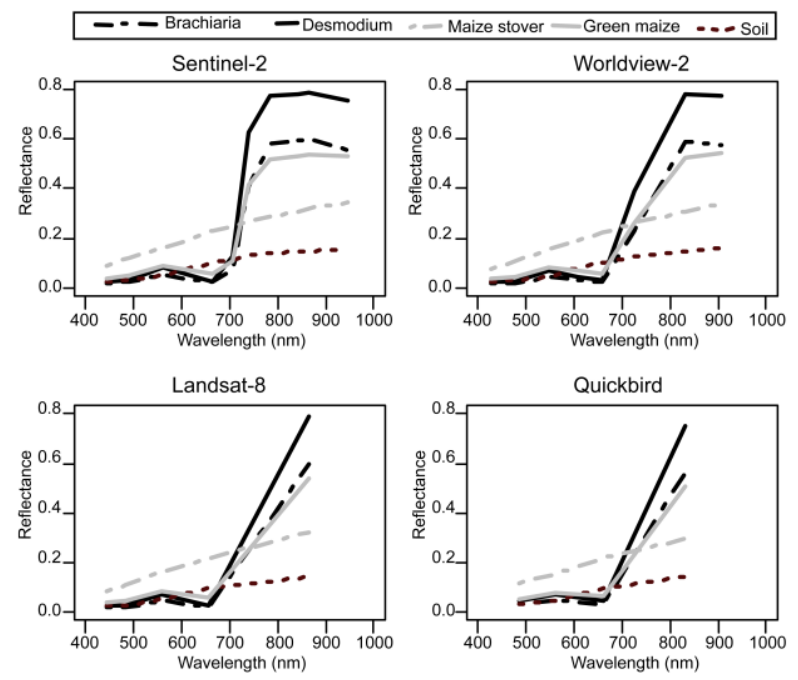

Figure 3. Mean canopy spectra of the 'push-pull' system components using the band configuration of four multispectral sensors 


\subsection{Model evaluation}

Sentinel-2 and WorldView-2 showed superiority in detecting and classifying among the five 'push-pull' components tested. The RF model replicates (10-fold cross-validation) used to classify the different components showed that the overall accuracy and Kappa statistic for Sentinel-2 and WorldView 2 were > 98\%, respectively. Comparatively, the classification performance using Landsat-8 and Quickbird was slightly lower ( $\pm 4 \%$ difference) than Sentinel-2 and Worldview-2.

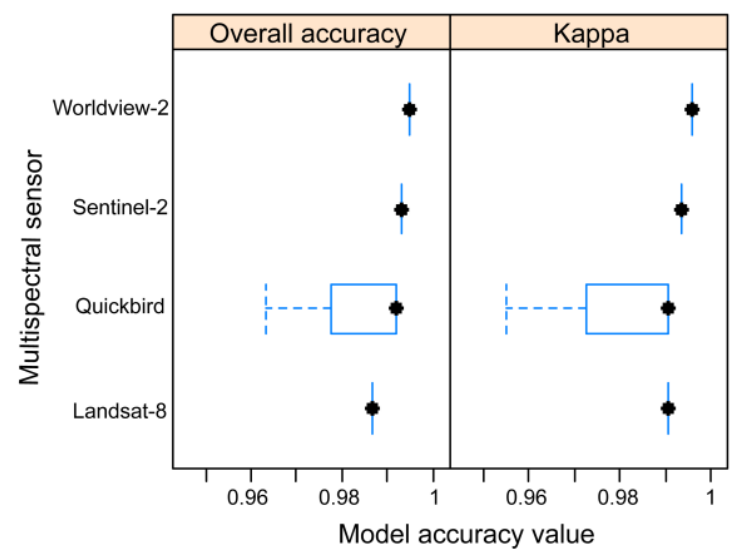

Figure 4. Models performance for separating the five 'pushpull' components as evaluated by overall accuracy and Kappa statistics, using all the resampled band configurations of four multispectral sensors

\section{DISCUSSION}

The findings from this current study showed that the companion crops can accurately be discriminated from crops and the soil components of the 'push-pull' system using the resampled multispectral wavebands and the RF discrimination algorithms. In this study, the results showed that the spectral behaviour of the companion crops and maize are very similar in pattern but differ in the magnitude of reflectance. Green maize is higher than both Brachiaria and Desmodium in the visible section of the EMS but lower in the NIR. This can be attributed to the differences in the leaf structure (leaf thickness, leaf mass, and leaf density) and the diversity of plant pigments occurring at different levels within the different co-occurring vegetation (Tesfamichael et al., 2018). A study by Serrano, (2008) demonstrated that thick leaves have a low correlation with chlorophyll content compared with thinner leaves. This could be the reason why green maize reflected more in the visible than both Brachiaria and Desmodium since the maize leaves are relatively thinner. Also, plant pigments are integrally related to the biological function and structure of the leaves. Chlorophyll absorbs light energy and allocates it to the photosynthetic system while, yellow pigments (carotenoids) also contribute energy to the photosynthetic apparatus and assist in resistance to environmental stress (Blackburn, 2007). Thus, these variations attributed to the differences in the reflectance of these components across the entire tested spectrum.

Additionally, anthocyanins (red, pink, and purple pigments) also gather reactive oxygen intermediates or act as antifungal compounds (Litchenthaler and Buschmann, 2001; Sims and Gamon, 2002). In light of the importance of pigments for leaf and petal function, dynamics in pigment quantities may provide details regarding their physiological state (Thenkabail et al.,
2013). For instance, chlorophyll tends to decline more rapidly than carotenoids when plants are under stress or during leaf senescence (Sims and Gamon, 2002). Thus, the reflectance response to incident radiation is influenced by the quantity and the interplay between the ratios of these pigments within the different plants (Blackburn, 2007), in our case the 'push-pull' companion crops. Using the hyperspectral data, we found that although the $530-570 \mathrm{~nm}$ are the portions which are mainly inclined to the green reflectance peak, all the plants had the highest peak at $550 \mathrm{~nm}$ within the visible region of the EMS, however, they differed significantly in the range $550-680 \mathrm{~nm}$ and in the NIR $(750-925 \mathrm{~nm})$ regions. This information is however masked out when using the four multispectral sensors. This makes the multispectral sensors, with strategically position red-edge bands robust and more useful than their counterparts that lack these bands such as Quickbird and Landsat-8 (Shoko and Mutanga, 2017). For instance, Sentinel-2 covers more critical waveband regions for vegetation i.e. 4 bands while Landsat- 8 covers only 2 critical waveband regions. Nonetheless, all the sensors tested in this study produced plausible accuracies and were demonstrated to be particularly useful in the detection and separation of the five 'push-pull' components examined. Sentinel-2 and Landsat- 8 , however, possess the additional advantages of being freely available and their relatively high temporal resolution (5 days revisit for Sentinel-2) (Makaya et al., 2019). RF provided plausible accuracies and modelling performance. The performance of RF, in this study, agrees with some studies that have utilized RF and leaf-level or canopylevel hyperspectral data to detect a plant trait (Litchenthaler and Buschmann, 2001; Tesfamichael et al., 2018; Thenkabail et al., 2013).

\section{CONCLUSIONS}

In this study, the possibilities of using canopy-level in-situ hyperspectral data for predicting five components of a 'pushpull' system are demonstrated. There is huge potential in widearea mapping using spaceborne data for the distinction between 'push-pull' and non 'push-pull' agricultural plots. Prediction and distinction of the components of 'push-pull' demonstrate satisfactory overall accuracies (> 95\% overall accuracy). The red-edge bands of the Sentinel-2 and Worldview-2 satellite sensors provided superiority in the classification and detection of 'push-pull' companion crops than their counterparts i.e. Landsat-8 and Quickbird. For more precise results, these results can be vindicated by using the images produced by these multispectral sensors on a field or landscape scale to enumerate and detect 'push-pull' plots. The machine learning RF classification algorithm emerged as a very robust and reliable model for classification and predictions. However, there is a need to investigate the temporal (crop age) and spatial variability (within different soil type backgrounds) of the different potential companion crop combinations to explore upscaling options for monitoring the adoption and productivity of the 'push-pull' plots.

\section{ACKNOWLEDGEMENTS}

We gratefully acknowledge the financial support for this research by the following organizations and agencies: Biovision Foundation for Ecological Development (Switzerland) and grant number (BV DPP-010/ 2019); UK's Department for International Development (DFID); Swedish International Development Cooperation Agency (Sida); the Swiss Agency for Development and Cooperation (SDC); Ethiopian and Kenyan Governments. "B.T. Mudereri" was supported by a German Academic Exchange Service (DAAD) In-Region Postgraduate Scholarship. In the same way, the authors express their gratitude 
to Grace Aduvukha for the help in data collection and Albert Baya for preparing the 'push-pull' plots. The views expressed herein do not necessarily reflect the official opinion of the donors.

\section{REFERENCES}

Abdel-Rahman, E.M., Mutanga, O., Adam, E., Ismail, R., 2014. Detecting Sirex noctilio grey-attacked and lightning-struck pine trees using airborne hyperspectral data, random forest and support vector machines classifiers. ISPRS Journal of Photogrammetry and Remote Sensing 88, 48-59. https://doi.org/10.1016/j.isprsjprs.2013.11.013

Adam, E., Deng, H., Odindi, J., Abdel-Rahman, E.M., Mutanga, O., 2017. Detecting the early stage of phaeosphaeria leaf spot infestations in maize crop using in situ hyperspectral data and guided regularized random forest algorithm. Journal of Spectroscopy 2017. https://doi.org/10.1155/2017/6961387

Blackburn, G.A., 2007. Hyperspectral remote sensing of plant pigments. Journal of Experimental Botany 58, 855-867. https://doi.org/10.1093/jxb/erl123

Chemura, A., Mutanga, O., Dube, T., 2017. Separability of coffee leaf rust infection levels with machine learning methods at Sentinel-2 MSI spectral resolutions. Precision Agriculture 18, 859-881.

https://doi.org/https://link.springer.com/article/10.1007/s11119016-9495-0

Dhau, I., Adam, E., Mutanga, O., Ayisi, K., Abdel-Rahman, E.M., Odindi, J., Masocha, M., 2018. Testing the capability of spectral resolution of the new multispectral sensors on detecting the severity of grey leaf spot disease in maize crop. Geocarto International 33, 1223-1236. https://doi.org/http://doi.org/10.1080/10106049.2017.1343391

FAO, IFAD, UNICEF, WFP, and W., 2019. The State of Food Security and Nutrition in the World 2019. Safeguarding against economic slowdowns and downturns. Rome, FAO Licence: CC BY-NC-SA 3.0 IGO.

Khan, Z., Midega, C.A.O., Hooper, A., Pickett, J., 2016. PushPull: Chemical ecology-based integrated pest management technology. Journal of Chemical Ecology 42, 689-697. https://doi.org/10.1007/s10886-016-0730-y

Khan, Z.R., Amudavi, D.M., Midega, C.A.O., Wanyama, J.M., Pickett, J.A., 2008. Farmers' perceptions of a "push-pull" technology for control of cereal stemborers and Striga weed in western Kenya. Crop Protection 27, 976-987. https://doi.org/10.1016/j.cropro.2007.12.001

Kuhn, M., Wing, J., Weston, S., Williams, A., Chris, A., Engelhardt, Tony, C., Mayer, Z., Kenke, B., The R CoreTeam, I., Michael, B., Reynald, L., Andrew, Z., Luca, S., Yuan, T., 2018. Caret: Classification and Regression Training. R package version $6.0-81$.

Litchenthaler, H.., Buschmann, C., 2001. Chlorophylls and carotenoids measurement and UV-vis characterization 1-8. https://doi.org/10.1002/0471709085.ch21

Lukas, W., Lehnert, Hanna, M., Joerg, B., 2018. hsdar: Manage, analyse and simulate hyperspectral data in $\mathrm{R}$. R package version 0.7.2.
Makaya, N.P., Mutanga, O., Kiala, Z., Dube, T., Seutloali, K.E., 2019. Assessing the potential of Sentinel-2 MSI sensor in detecting and mapping the spatial distribution of gullies in a communal grazing landscape. Physics and Chemistry of the Earth 112, 66-74. https://doi.org/10.1016/j.pce.2019.02.001

Midega, C.A.O., Bruce, T.J.A., Pickett, J.A., Pittchar, J.O., Murage, A., Khan, Z.R., 2015. Climate-adapted companion cropping increases agricultural productivity in East Africa. Field Crops Research 180, 118-125. https://doi.org/10.1016/j.fcr.2015.05.022

Midega, C.A.O., Pittchar, J.O., Pickett, J.A., Hailu, G.W., Khan, Z.R., 2018. A climate-adapted push-pull system effectively controls fall armyworm, Spodoptera frugiperda (J E Smith), in maize in East Africa. Crop Protection 105, 10-15. https://doi.org/10.1016/j.cropro.2017.11.003

Mudereri, B.T., Abdel-Rahman, E.M., Dube, T., Landmann, T., Khan, Z.R., Kimathi, E., Owino, R., Niassy, S., 2020a. Multisource spatial data-based invasion risk modeling of Striga (Striga asiatica) in Zimbabwe. GIScience \& Remote Sensing 57, 553-571. https://doi.org/10.1080/15481603.2020.1744250

Mudereri, B.T., Dube, T., Adel-Rahman, E.M., Niassy, S., Kimathi, E., Khan, Z., Landmann, T., 2019. A comparative analysis of PlanetScope and Sentinel-2 space-borne sensors in mapping Striga weed using Guided Regularised Random Forest classification ensemble. ISPRS-International Archives of the Photogrammetry, Remote Sensing and Spatial Information Sciences XLII-2/W13, 701-708. https://doi.org/10.5194/isprsarchives-XLII-2-W13-701-2019

Mudereri, B.T., Dube, T., Niassy, S., Kimathi, E., Landmann, T., Khan, Z., Abdel-Rahman, E.M., 2020b. Is it possible to discern Striga weed (Striga hermonthica) infestation levels in maize agro-ecological systems using in-situ spectroscopy? International Journal of Applied Earth Observation and Geoinformation $\quad 85, \quad 102008$. https://doi.org/10.1016/j.jag.2019.102008

Pickett, J.A., Woodcock, C.M., Midega, C.A.O., Khan, Z.R., 2014. Push-pull farming systems. Current Opinion in Biotechnology 26, 125-132. https://doi.org/10.1016/j.copbio.2013.12.006

$\mathrm{R}$ Core Team, 2020. R: A language and environment for statistical computing. R Foundation for Statistical Computing, Vienna, Austria. URL https://www.R-project.org/.

Serrano, L., 2008. Effects of leaf structure on reflectance estimates of chlorophyll content. International Journal of Remote Sensing 29, 5265-5274. https://doi.org/10.1080/01431160802036359

Shoko, C., Mutanga, O., 2017. Examining the strength of the newly-launched Sentinel 2 MSI sensor in detecting and discriminating subtle differences between $\mathrm{C} 3$ and $\mathrm{C} 4$ grass species. ISPRS Journal of Photogrammetry and Remote Sensing 129

$32-40$ https://doi.org/https://doi.org/10.1016/j.isprsjprs.2017.04.01601 6

Sims, D.A., Gamon, J.A., 2002. Relationships between leaf pigment content and spectral reflectance across a wide range of species. Remote sensing of the environment 81, 337-354. 
https://doi.org/10.1016/S0034-4257(02)00010-X

Tesfamichael, S.G., Newete, S.W., Adam, E., Dubula, B., 2018. Field spectroradiometer and simulated multispectral bands for discriminating invasive species from morphologically similar cohabitant plants. GIScience and Remote Sensing 55, 417-436. https://doi.org/10.1080/15481603.2017.1396658

Thenkabail, P., Mariotto, I., Gumma, M., 2013. Selection of hyperspectral narrowbands (HNBs) and composition of hyperspectral twoband vegetation indices (HVIs) for biophysical characterization and discrimination of crop types using field reflectance and Hyperion/EO-1 Data. IEEE Journal of Selected Topics in Applied Earth Observations and Remote Sensing 6 , $427-439$.

https://doi.org/10.1109/JSTARS.2013.2252601 